\title{
Seasonal differences in brown adipose tissue density and pulse rate variability in a thermoneutral environment
}

\author{
Shinsuke Nirengi ${ }^{1}$, Naoki Sakane ${ }^{1}$, Shiho Amagasa ${ }^{2}$, Sawako Wakui ${ }^{3}$, Toshiyuki Homma ${ }^{4}$, Yuko Kurosawa ${ }^{5}$ \\ and Takafumi Hamaoka ${ }^{5 *}$
}

\begin{abstract}
Background: Brown adipose tissue (BAT) is sympathetically activated and induces thermogenesis during cold exposure, thereby influencing energy expenditure and body fat levels. The very low frequency (VLF) components of pulse rate variability could be a form of thermogenic sympathetic nervous activity, but no clear relationship has yet been reported between VLF activity and BAT density. We therefore aimed to evaluate the association between them.

Methods: We enrolled 20 adults in winter and 20 matched adults in summer. We assessed BAT densities based on total hemoglobin concentrations ([total-Hb]) measured with near-infrared time-resolved spectroscopy. We calculated VLF activity from pulse rate variability measurements.

Results: BAT density ([total-Hb]; winter $70.5 \pm 17.0 \mu \mathrm{M}$, summer $57.8 \pm 18.3 \mu \mathrm{M}$ ) and VLF activity (winter $6.7 \pm 0.8$, summer $6.1 \pm 0.9)$ were significantly higher in winter than in summer $(P<0.05)$. However, there was no significant correlation between VLF activity and BAT density in either season.
\end{abstract}

Conclusion: Each parameter exhibited seasonal variation, but we failed to observe any significant correlations.

Keywords: Near-infrared time-resolved spectroscopy, Brown adipose tissue, Seasonality, Autonomic nervous system

\section{Background}

The obesity pandemic necessitates effective therapies to prevent consequent diseases. In mammals, adipose tissue is found in two forms: white adipose tissue and brown adipose tissue (BAT) [1]. White adipose tissue stores energy in the form of triacylglycerol, whereas BAT is important for thermogenesis and homeostasis in small mammals. BAT activation in mice promotes energy expenditure, reduces adiposity, and protects against diet-induced obesity [2]. BAT activation is therefore being investigated as an anti-obesity tool.

Functional BAT was recently detected in healthy adults using ${ }^{18} \mathrm{~F}$-fluorodeoxyglucose positron emission tomography combined with computed tomography $\left({ }^{18} \mathrm{FDG}-\mathrm{PET} / \mathrm{CT}\right)$ [3-6]. Intriguingly, BAT is more often observed in lean individuals than in obese ones [3], as is

\footnotetext{
* Correspondence: kyp02504@nifty.com

${ }^{5}$ Department of Sports Medicine for Health Promotion, Tokyo Medical

University, 6-1-1 Shinjuku, Shinjuku-ku, Tokyo 160-8402, Japan

Full list of author information is available at the end of the article
}

the case in animals [1]. The BAT provides non-shivering thermogenesis through sympathetic nervous system (SNS) activity in animals [1]. BAT activity and mass increase in winter [3-7], and they may be related to SNS activity in humans. Indeed, $\beta_{3}$-adrenergic agonists [8] and consumption of foods [9] that promote SNS activity [10] increase BAT activity and mass in humans, but no reports have yet identified a relationship between BAT mass and SNS activity in humans. Near-infrared time-resolved spectroscopy (NIR $\mathrm{NRS}_{\mathrm{TR}}$ ) is a method for evaluating BAT density that is simpler and less invasive than ${ }^{18}$ FDG-PET/CT $[9,11,12]$. NIR TRS permits evaluations of BAT vascularity, which can be used to assess BAT

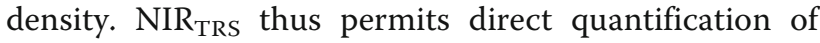
BAT rather than of physiological reactions. Indeed, our previous study [11] showed that BAT activity and mass, as evaluated with ${ }^{18} \mathrm{FDG}-\mathrm{PET} / \mathrm{CT}$, are related to BAT density, as evaluated with $\mathrm{NIR}_{\mathrm{TRS}}(r=0.73)$, under both thermoneutral and cold conditions. Furthermore, our longitudinal study [9] showed that the total hemoglobin 
concentration ([total-Hb]) positively correlates with BAT activity, as measured with ${ }^{18} \mathrm{FDG}-\mathrm{PET} / \mathrm{CT}$, during repeated thermogenic capsiate intake, which is known to increase BAT activity and mass in both sexes. NIR $\mathrm{TRS}_{\text {therefore }}$ permits BAT density evaluations without cold exposure.

Pulse rate variability (PRV) measurements are used in clinical practice and research to noninvasively estimate autonomic nervous system (ANS) function [13, 14] and heart rate variability [15]. The PRV frequency domain method can distinguish high-frequency ( $\mathrm{HF}>25 \mathrm{~Hz}$ ) components that purely reflect parasympathetic nervous system (PNS) activity from low-frequency $(\mathrm{LF}<0.15 \mathrm{~Hz})$ and very low frequency (VLF 0.003-0.15 Hz) components that reflect SNS [16] and PNS activities [17]. A previous study [18] reported that SNS activity is elevated in winter. Parts of the VLF band much lower than $0.1 \mathrm{~Hz}$ may reflect thermoregulatory control $[19,20]$, so the VLF activation observed in response to thermogenic stimuli implies that VLF-associated activity reflects thermogenic regulation, which in turn reflects regulation of energy metabolism primarily performed by the SNS $[16,21,22]$. In contrast, a study that used pharmacological blockade methods [17] suggested that the VLF band predominantly reflects parasympathetic contributions.

Because BAT is thermogenic and is regulated solely by the SNS, its activity may be related to VLF activity. However, no studies have investigated the relationship between BAT density and VLF activity. We therefore aimed to compare SNS activity, especially VLF-reflected SNS activity, in winter and summer using the PRV frequency domain method and to test the relationship between BAT density and VLF activity.

\section{Methods}

This study was conducted in the summer and winter of 2014 in Shiga Prefecture, Japan. The study protocols were approved by Ritsumeikan University's Institutional Review Board (approval number: 2013-036) and performed in accordance with the principles of the Declaration of Helsinki (Fortaleza 2013). Written informed consent was obtained from all participants.

\section{Subjects}

We recruited university students with poster advertisements and emails to the student body. The volunteers included 42 men and 18 women. After excluding habitual smokers, heavy drinkers $(>30 \mathrm{~g}$ of ethanol per day), and subjects who took medications, we assigned 20 students each to the summer and winter groups. These two groups were matched in age, sex, and body mass index (BMI) (Fig. 1).

The subjects were instructed to avoid high-intensity physical activity on the days before and of the test. The women were measured during their luteal phases as predicted from their menstrual cycles and last menstruations.

\section{Anthropometric and blood pressure parameter measurements}

We evaluated the body mass, fat mass, percent body fat, lean body mass, and bone mass of each subject with a Lunar Prodigy dual-energy X-ray absorptiometer (GE Healthcare, Chicago, IL). After allowing the subjects to rest for $10 \mathrm{~min}$, we measured their systolic blood pressure, diastolic blood pressure, and heart rate using an HBP-9020 automated sphygmomanometer (Omron, Kyoto, Japan).

\section{BAT density measurements}

We determined BAT density in the supraclavicular region by measuring the [total- $\mathrm{Hb}$ ] using a TRS-20 NIR TRS $_{\text {device }}$

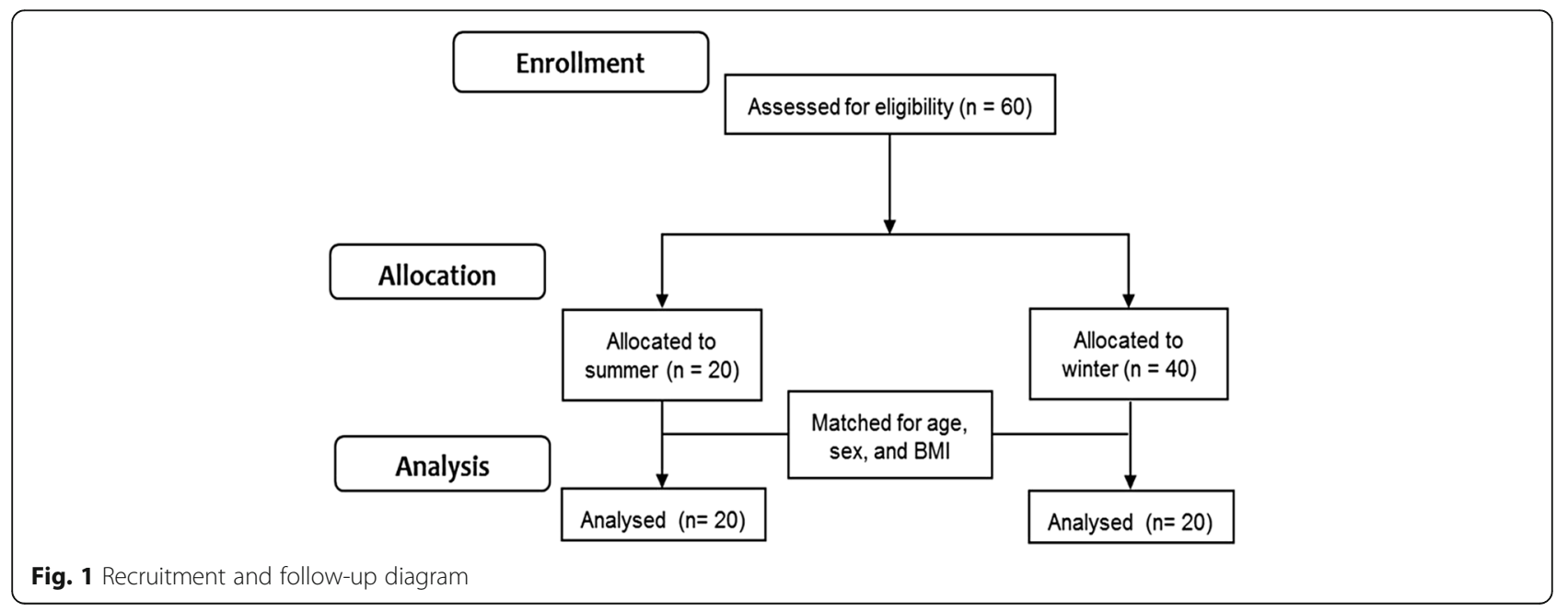


(Hamamatsu Photonics, Hamamatsu, Japan) for $5 \mathrm{~min}$ at $27{ }^{\circ} \mathrm{C}$ as previously described $[9,11,12]$. The distance between the emitter and detector was set at $30 \mathrm{~mm}$ [23].

The tissue was illuminated with 100-ps pulses of 760-, $800-$, and $830-\mathrm{nm}$ light from a $200-\mu \mathrm{m}$ core diameter optical fiber with a 100-ps full-width at half-maximum, a $5-\mathrm{MHz}$ repetition rate, and an $80-\mu \mathrm{W}$ average power at each wavelength. The emitted photons penetrated the tissue and were reflected to a 3-mm diameter optical bundle fiber, through which they were sent to a photomultiplier tube for single-photon detection and a signal processing circuit for time-resolved measurement. Using the non-linear least squares method, the digitized temporal profile data from an in vitro sample or tissue were fitted with a theoretical temporal profile derived from the analytical solution of photon diffusion theory with a semi-infinite homogeneous model in reflectance mode. After convolution with the instrumental response function such that the time response of the instrument itself could be compensated for, the absorption coefficients and reduced scattering coefficients at 760 , 800 , and $830 \mathrm{~nm}$ were obtained. The absolute [total- $\mathrm{Hb}$ ] values were then determined using a least squares fitting method [19]. The NIR ${ }_{\text {TRS }}$ system collected data at a $0.1-\mathrm{Hz}$ sampling rate. The coefficient of variation for repeated [total-Hb] measurements was $4.9 \%$ [11].

\section{ANS parameters}

PRV was measured using a sphygmograph (TAS9 Pulse Analyzer Plus, YKC, Tokyo, Japan) for $15 \mathrm{~min}$ at $27{ }^{\circ} \mathrm{C}$ with subjects in the supine position and wearing light clothing. The frequency domain information was automatically analyzed with a fast Fourier transform [24, 25]. This analysis involved 1000 samples, a 300-ms pulse interval resampling frequency, and a Hanning window function. The correspondence of PRV with heart rate variability in the resting state is well documented $[13,26]$. We defined the VLF, LF, HF, and total power (TP) components as the areas under the spectral peaks within the $0.0033-0.04 \mathrm{~Hz}, 0.04-0.15 \mathrm{~Hz}$, $0.15-0.4 \mathrm{~Hz}$, and $0.0033-0.4 \mathrm{~Hz}$ ranges, respectively. We assessed sympathetic activity by calculating the LF to HF ratio (LF/HF).

\section{Dietary intake and physical activity recordings}

Dietary habits during the preceding month were assessed using a validated, brief, self-administered diet history questionnaire that queried the consumption frequencies for 56 foods and beverages and 9 dishes that are commonly consumed in Japan. Daily intakes of energy, proteins, fats, and carbohydrates were calculated from the responses [27]. Daily steps and activity-related energy expenditures were estimated using Health Counter HJ-710IT pedometers (Omron Healthcare Corp., Kyoto, Japan), and weekly means were calculated.

\section{Statistical analyses}

Data are expressed as means \pm standard deviations. The ANS parameters were not normally distributed (Shapiro-Wilk test, $P<0.05$ ), so they were logtransformed. We initially used Student's $t$ test for between-season comparisons of ANS parameters and then repeated the comparisons for significant differences using analysis of covariance after controlling for age, sex, BMI, and log-TP. We tested for partial correlations between ANS parameters and anthropometric parameters while controlling for age and sex. The analysis of covariance data was expressed as means and 95\% confidence intervals $(95 \% \mathrm{CI})$. We calculated Pearson correlation coefficients for simple correlation analyses. Statistical significance was defined as $P<0.05$. Pairmatching was performed using Easy $\mathrm{R}$ software (Saitama Medical Center, Jichi Medical University, Saitama, Japan) [28], but all other statistical analyses were performed using SPSS version 19 (IBM, Armonk, NY).

\section{Results}

Table 1 shows the anthropometric and blood pressure measurements in each season. There were no significant between-season differences in height, bodyweight, BMI,

Table 1 Participant characteristics

\begin{tabular}{llll}
\hline Variables & $\begin{array}{l}\text { Summer } \\
(n=20)\end{array}$ & $\begin{array}{l}\text { Winter } \\
(n=20)\end{array}$ & $P$ value \\
\hline Age, years & $21.0 \pm 1.2$ & $20.6 \pm 0.9$ & 0.19 \\
Female, \% & 40 & 40 & - \\
Height, cm & $165.7 \pm 9.1$ & $166.0 \pm 6.6$ & 0.90 \\
Body weight, kg & $68.3 \pm 14.6$ & $64.9 \pm 13.3$ & 0.45 \\
BMl, kg/m ${ }^{2}$ & $24.7 \pm 4.0$ & $23.4 \pm 3.6$ & 0.28 \\
Body fat, \% & $26.0 \pm 8.5$ & $23.7 \pm 6.0$ & 0.33 \\
Fat mass, kg & $17.6 \pm 9.2$ & $14.2 \pm 5.0$ & 0.16 \\
Lean body mass, kg & $47.6 \pm 7.8$ & $47.2 \pm 9.5$ & 0.89 \\
Bone mass, kg & $2.9 \pm 0.4$ & $2.8 \pm 0.5$ & 0.38 \\
SBP, mmHg & $118.6 \pm 17.6$ & $120.1 \pm 10.5$ & 0.74 \\
DBP, mmHg & $64.4 \pm 14.4$ & $66.4 \pm 7.8$ & 0.60 \\
Heart rate, bpm & $71.2 \pm 12.9$ & $65.1 \pm 8.8$ & 0.09 \\
Steps, per day & $7060.6 \pm 2478.8$ & $7690.1 \pm 2027.8$ & 0.39 \\
Energy expenditure, kcal/day & $218.5 \pm 93.2$ & $193.0 \pm 64.2$ & 0.32 \\
Energy intake, kcal/day & $1997 \pm 718$ & $1787 \pm 682$ & 0.35 \\
Protein intake, g/day & $63.4 \pm 22.7$ & $63.5 \pm 25.2$ & 0.99 \\
Fat intake, g/day & $58.0 \pm 22.5$ & $57.4 \pm 19.9$ & 0.93 \\
Carbohydrate intake, g/day & $293.7 \pm 110.3$ & $239.9 \pm 101.6$ & 0.12 \\
\hline Data re repored as means stand & &
\end{tabular}

Data are reported as means \pm standard deviations

$B M I$ body mass index, $D B P$ diastolic blood pressure, SBP systolic blood pressure 
body fat mass, body fat proportions, bone mass, blood pressure, heart rate, physical activity (step numbers and energy expenditure), or dietary intake of fats, proteins, carbohydrates, or total calories.

The [total-Hb] as an index of BAT density was higher in winter than in summer $(70.5 \pm 17.0 \mu \mathrm{M}$ vs. $57.8 \pm$ $18.3 \mu \mathrm{M}$, respectively; $P<0.01$ ) (Table 2 ). After controlling for age, sex, BMI, and log-TP, we still observed significant between-season differences in the [total-Hb] $(58.2$ [95\% CI 50.0 to 66.5$] \mu \mathrm{M}$ in winter vs. 70.9 [62.7 to 79.2] $\mu \mathrm{M}$ in summer; $P<0.01)$. Among the ANS parameters, the $\log$-HF PRV components were significantly lower in winter than in summer $(6.2 \pm 0.7$ vs. $7.0 \pm 1.2$, respectively; $P<0.05)$. Of the SNS parameters, the log-LF PRV components were not significantly different between seasons, but the log-VLF PRV components were significantly higher in winter than in summer $(6.7 \pm 0.8$ vs. $6.1 \pm 0.9$, respectively; $P<0.05)$, as were the $\mathrm{LF} / \mathrm{HF}$ ratios $(1.1 \pm 0.1$ vs. $0.9 \pm 0.1$, respectively; $P<0.01$ ) (Table 2). After controlling for age, sex, BMI, and log-TP, we still observed significant between-season differences in the log-VLF PRV components (6.7 [95\% CI 6.5 to 7.0] in winter vs. 6.0 [5.8 to 6.2] in summer; $P<0.01$ ), log-HF PRV components $(6.3[6.1$ to 6.5$]$ in winter vs. 7.0 [6.7 to 7.2$]$ in summer; $P<0.05)$, and $\log$-LF/HF ratios (1.1 [1.0 to 1.1] in winter vs. 0.9 [0.9 to 1.0$]$ in summer; $P<0.01$ ). No ANS parameter correlated with daily steps or activity-related energy expenditure. The only significant relationship between ANS parameters and anthropometric parameters after adjusting for age and sex was that between logVLF and body fat mass (Table 3). After adjusting for age and sex, the [total-Hb] negatively correlated with BMI $(r=-0.51, P<0.05)$, body fat $(-0.65, P<0.05)$, and fat mass $(r=-0.62, P<0.05)$ but did not significantly correlate with $\log$-TP $(r=0.12, P=0.47), \log$-LF PRV components $(r=0.10, P=0.96)$, log-VLF PRV components $(r=0.13, P=0.26)$, log-HF PRV components $(r=0.09$,

Table 2 BAT density and autonomic parameters in summer and winter

\begin{tabular}{llll}
\hline Variables & $\begin{array}{l}\text { Summer } \\
(n=20)\end{array}$ & $\begin{array}{l}\text { Winter } \\
(n=20)\end{array}$ & $P$ value \\
\hline BAT density, $\mu M$ & $57.8 \pm 18.3$ & $70.5 \pm 17.0$ & $<0.05$ \\
Autonomic parameters & & & \\
Log-TP & $7.8 \pm 1.0$ & $7.7 \pm 0.6$ & 0.63 \\
Log-LF & $6.5 \pm 1.0$ & $6.5 \pm 0.7$ & 0.83 \\
Log-VLF & $6.1 \pm 0.9$ & $6.7 \pm 0.8$ & $<0.05$ \\
Log-HF & $7.0 \pm 1.2$ & $6.2 \pm 0.7$ & $<0.05$ \\
Log-LF/HF & $0.9 \pm 0.1$ & $1.1 \pm 0.1$ & $<0.01$ \\
\hline
\end{tabular}

Data are reported as means \pm standard deviations BAT density was evaluated from total hemoglobin concentrations measured with near-infrared time resolved spectroscopy in the supraclavicular region $B A T$ brown adipose tissue; $H F$ high-frequency; $L F$ low-frequency; $L F / H F$ LF to HF; TP total power; VLF very low frequency
$P=0.57)$, or $\log -\mathrm{LF} / \mathrm{HF}$ ratios $(r=0.02, \quad P=0.44)$. These relationships were not observed in either summer or winter alone. There was therefore no significant relationship between BAT density and any ANS index (Table 3).

\section{Discussion}

Our objective was to evaluate seasonal differences in PRV components reflective of ANS activity, and we succeeded in obtaining the first evidence that the VLF PRV components are greater in winter than in summer even after controlling for confounders. Further, the LF/ HF ratio, which reflects SNS activity, and the HF PRV components, which reflect PNS activity, were higher and lower, respectively, in winter than in summer.

ANS measurements are widely used for predictions and diagnoses in both clinical practice and laboratory studies [15]. ANS studies have normally been conducted in environments well controlled for factors such as room temperature, but they have not often considered seasonal differences. In many countries, winter is associated with elevated mortality and hospitalization rates, especially from cardiovascular diseases $[29,30]$, and it is speculated that this arises from environmental temperature differences [31-33]. Many studies have clearly shown the role of the ANS in cardiovascular pathophysiology [34, 35]. This lends plausibility to our observation of seasonal variations in ANS activity. A few other studies have reported seasonal variations in sympathetic activity $[18,36]$, such as the observation that winter is associated with elevated resting muscle sympathetic nerve burst rates [18] and plasma norepinephrine concentrations [36] and lower variability in coupling intervals between normal beats [37]. Our results are consistent with those of these studies and provide new information about the VLF PRV components. We think that VLF PRV primarily reflects sympathetic thermogenic activities. Previous studies showed that thermogenic perturbations such as acute cold exposure or consumption of spicy foods containing capsaicin selectively increased VLF activity in persons of normal weight but not in persons with obesity $[16,21,22]$. Furthermore, we observed that VLF activity was increased in winter, but that HF activity was decreased in winter. However, we cannot rule out the possibility that PNS activity contributes to VLF activity because a previous study showed that pharmacologically blockading parasympathetic signals attenuated VLF activity [17].

Studies evaluating BAT activity with ${ }^{18}$ FDG-PET/CT report that it increases in winter $[3,7]$ and that its mechanism might be related to SNS activity. This is consistent with our observation of elevated [total- $\mathrm{Hb}$ ], an index of BAT density, in winter. However, we observed no correlation between [total-Hb] and SNS activity, and 
Table 3 Relationship between anthropometric parameters and heart rate variability components representative of the autonomic nervous system

\begin{tabular}{|c|c|c|c|c|c|c|}
\hline & $\mathrm{BMI}$ & $\%$ Body fat & Fat mass & Lean body mass & Bone mass & BAT density \\
\hline Log-TP & -0.12 & -0.25 & -0.30 & -0.02 & -0.07 & 0.12 \\
\hline Log-LF & 0.00 & -0.20 & -0.21 & 0.07 & -0.07 & 0.11 \\
\hline Log-VLF & -0.24 & -0.22 & -0.31 & -0.17 & -0.24 & 0.13 \\
\hline Log-HF & -0.07 & -0.21 & -0.24 & 0.03 & 0.07 & 0.11 \\
\hline $\mathrm{LF} / \mathrm{HF}$ & 0.04 & 0.04 & 0.07 & 0.03 & -0.14 & -0.04 \\
\hline
\end{tabular}

BAT density was evaluated by examining total hemoglobin concentrations with near-infrared time resolved spectroscopy in the supraclavicular region. Partial correlation analyses were conducted with adjustments for age and sex

$B A T$ brown adipose tissue, HF high frequency; $L F$ low frequency, LF/HF LF to HF, TP total power, VLF very low frequency

no other PRV study has observed a correlation between BAT density and SNS activity in humans either. This is inconsistent with studies of other SNS-related parameters. BAT activity is increased by $\beta 3$-adrenergic agonists $[8,38]$ and inhibited by $\beta$-adrenergic antagonists [39]. ${ }^{123}$ I-metaiodobenzylguanidine imaging, which evaluates sympathetic activity, can visualize BAT activity [40]. Surprisingly, ${ }^{18}$ FDG-PET/CT scans in patients with Horner's syndrome reveal less BAT activity on the neuropathy-affected side than on the unaffected side [41]. Furthermore, patients with pheochromocytoma who exhibit high plasma total metanephrine levels have greater BAT activity than those who exhibit low total metanephrine levels [42]. These studies suggest that human BAT activity is related to SNS activity, though it may also be related to certain humoral substances that can reportedly increase BAT density, such as myokines [43, 44], thyroid hormones [44], and lipokines [45].

We observed no significant between-season differences in blood pressure, but some large studies observed small between-season differences in systolic and diastolic blood pressure that occur in middle-aged individuals and might increase with age [32, 33, 46]. Our participants may have been too few and too young for us to detect such differences.

Our study has several limitations. First, the two groups were composed of different individuals, and the sample size was relatively small. Therefore, although we conducted sex-matching and adjustments for sex, we could not separately analyze the data of men and women. A thorough understanding and careful implementation of a within-subject design will therefore be necessary in future studies. Second, we did not apply cold stimulation. A previous study reported that energy expenditures do not significantly differ between BAT-negative and BAT-positive subjects at thermoneutral temperatures but are significantly higher in BAT-positive subjects at cold temperatures [47]. Therefore, SNS activity might be greater in subjects with high BAT densities if cold exposure were applied. Third, we did not include subjects with extremely high BAT densities, and the correlation coefficients might have been stronger had we included them. Fourth, the NIR ${ }_{T R S}$ method was confined to measuring $4-\mathrm{cm}^{3}$ volumes and could not permit BAT activity evaluations under cold conditions. Future studies should use ${ }^{18}$ FDG-PET/CT to investigate ANS function and BAT activity during cold exposure in humans.

\section{Conclusions}

In conclusion, we showed that the VLF PRV components and the LF/HF ratios were greater in winter than in summer, concomitant with seasonal changes in BAT density, whereas the ANS-related HF PRV components exhibited the opposite seasonal pattern. However, we found no significant correlations between VLF activity and BAT density.

\begin{abstract}
Abbreviations
[total-Hb]: Total hemoglobin concentration; ${ }^{18} \mathrm{FDG}-\mathrm{PET} / \mathrm{CT}:{ }^{18} \mathrm{~F}$-fluorodeoxyglucose positron emission tomography combined with computed tomography; ANS: Autonomic nervous system; BAT: Brown adipose tissue; HF: High frequency; LF: Low frequency; NIRTRS: Near-infrared time-resolved spectroscopy; PNS: Parasympathetic nervous system; PRV: Pulse rate variability; SNS: Sympathetic nervous system; VLF: Very low frequency
\end{abstract}

\section{Acknowledgements}

The authors wish to acknowledge the volunteers who participated in this study.

Funding

This work was supported by a Grant-in-Aid for Scientific Research from the Ministry of Education, Culture, Sports, Science, and Technology of Japan (16K16572 and 15H03100)

\section{Availability of data and materials}

The datasets analyzed in this study are not publicly available due to a privacy policy but are available from the corresponding author on reasonable request.

\section{Authors' contributions}

SN and TH designed the study. SN, SA, SW, TH, and YK collected and assembled the data. SN prepared the manuscript. SN, SA, and NS performed the statistical analysis. NS, SW, TH, YK, and TH helped to draft the manuscript and participated in its critical revision and the trial management. All authors read and approved the final manuscript.

\section{Ethics approval and consent to participate}

All subjects gave their written informed consent before enrolling in the study. The study was performed in accordance with the guidelines of the Declaration of Helsinki and was approved by the Ritsumeikan University's Institutional Review Board (approval number: 2013-036), Kusatsu, Japan. 


\section{Consent for publication}

All participants gave written informed consent for publication after a complete explanation of this study.

\section{Competing interests}

The authors declare that they have no competing interests.

\section{Publisher's Note}

Springer Nature remains neutral with regard to jurisdictional claims in published maps and institutional affiliations.

\section{Author details}

${ }^{1}$ Division of Preventive Medicine, Clinical Research Institute, National Hospital Organization Kyoto Medical Center, 1-1 Mukaihata-cho, Fukakusa, Kyoto 612-8555, Japan. ${ }^{2}$ Department of Preventive Medicine and Public Health, Tokyo Medical University, 6-1-1 Shinjuku, Shinjuku-ku, Tokyo 160-8402, Japan. ${ }^{3}$ Faculty of Health and Sports Science, Juntendo University, 1-1

Hiragagakuendai, Inzai, Chiba 270-1695, Japan. ${ }^{4}$ Faculty of Sports and Health Science, Daito Bunka University, 560 Iwadono, Higashimatsuyama-shi, Saitama 355-8501, Japan. ${ }^{5}$ Department of Sports Medicine for Health Promotion, Tokyo Medical University, 6-1-1 Shinjuku, Shinjuku-ku, Tokyo 160-8402, Japan

\section{Received: 4 October 2017 Accepted: 14 February 2018}

\section{Published online: 21 February 2018}

\section{References}

1. Cannon B, Nedergaard J. Brown adipose tissue: function and physiological significance. Physiol Rev. 2004;84:277-359.

2. Guerra C, Koza RA, Yamashita H, Walsh K, Kozak LP. Emergence of brown adipocytes in white fat in mice is under genetic control. Effects on body weight and adiposity. J Clin Invest. 1998;102:412-20.

3. Saito M, Okamatsu-Ogura Y, Matsushita M, Watanabe K, Yoneshiro T, Nio-Kobayashi J, Iwanaga T, et al. High incidence of metabolically active brown adipose tissue in healthy adult humans: effects of cold exposure and adiposity. Diabetes. 2009:58:1526-31.

4. Cypess AM, Lehman S, Williams G, Tal I, Rodman D, Goldfine AB, et al. Identification and importance of brown adipose tissue in adult humans. N Engl J Med. 2009;360:1509-17.

5. van Marken Lichtenbelt WD, Vanhommerig JW, Smulders NM, Drossaerts JM, Kemerink GJ, Bouvy ND, et al. Cold-activated brown adipose tissue in healthy men. N Engl J Med. 2009;360:1500-8.

6. Virtanen KA, Lidell ME, Orava J, Heglind M, Westergren R, Niemi T. Functional brown adipose tissue in healthy adults. N Engl J Med. 2009;360:1518-25.

7. Au-Yong IT, Thorn N, Ganatra R, Perkins AC, Symonds ME. Brown adipose tissue and seasonal variation in humans. Diabetes. 2009:58:2583-7.

8. Cypess AM, Weiner LS, Roberts-Toler C, Franquet Elía E, Kessler SH, Kahn PA, et al. Activation of human brown adipose tissue by a $\beta 3$-adrenergic receptor agonist. Cell Metab. 2015;21:33-8.

9. Nirengi S, Homma T, Inoue N, Sato H, Yoneshiro T, Matsushita M, et al. Assessment of human brown adipose tissue density during daily ingestion of thermogenic capsinoids using near-infrared time-resolved spectroscopy. J Biomed Opt. 2016:21:91305.

10. Hachiya S, Kawabata F, Ohnuki K, Inoue N, Yoneda H, Yazawa S, et al. Effects of $\mathrm{CH}$-19 Sweet, a non-pungent cultivar of red pepper, on sympathetic nervous activity, body temperature, heart rate, and blood pressure in humans. Biosci Biotechnol Biochem. 2007;71:671-6.

11. Nirengi S, Yoneshiro T, Sugie H, Saito M, Hamaoka T. Human brown adipose tissue assessed by simple noninvasive near-infrared time-resolved spectroscopy. Obesity (Silver Spring). 2015;23:973-80.

12. Nirengi S, Amagasa S, Homma T, Yoneshiro T, Matsumiya S, Kurosawa Y, Sakane N, et al. Daily ingestion of catechin-rich beverage increases brown adipose tissue density and decreases extramyocellular lipids in healthy young women. Springerplus. 2016;5:1363.

13. Schäfer A, Vagedes J. How accurate is pulse rate variability as an estimate of heart rate variability? A review on studies comparing photoplethysmographic technology with an electrocardiogram. Int J Cardiol. 2013;166:15-29.

14. Colombo R, Raimondi F, Corona A, Marchi A, Borghi B, Pellegrin S, et al. Pulse photoplethysmographic amplitude and heart rate variability during laparoscopic cholecystectomy: a prospective observational study. Eur J Anaesthesiol. 2017:34:526-33.
15. Xhyheri B, Manfrini O, Mazzolini M, Pizzi C, Bugiardini R. Heart rate variability today. Prog Cardiovasc Dis. 2012:55:321-31.

16. Matsumoto T, Miyawaki C, Ue H, Kanda T, Yoshitake Y, Moritani T. Comparison of thermogenic sympathetic response to food intake between obese and non-obese young women. Obes Res. 2001;9:78-85.

17. Taylor JA, Carr DL, Myers CW, Eckberg DL. Mechanisms underlying very-low-frequency RR-interval oscillations in humans. Circulation. 1998;98:547-55.

18. Cui J, Muller MD, Blaha C, Kunselman AR, Sinoway LI. Seasonal variation in muscle sympathetic nerve activity. Physiol Rep. 2015;3:e12492.

19. Akselrod S, Gordon D, Ubel FA, Shannon DC, Berger AC, Cohen RJ. Power spectrum analysis of heart rate fluctuation: a quantitative probe of beat-to-beat cardiovascular control. Science. 1981;213:220-2.

20. Eckberg DL, Kuusela TA. Human vagal baroreflex sensitivity fluctuates widely and rhythmically at very low frequencies. J Physiol. 2005;567:1011-9.

21. Matsumoto T, Miyawaki T, Ue H, Kanda T, Zenji C, Moritani T. Autonomic responsiveness to acute cold exposure in obese and non-obese young women. Int J Obes Relat Metab Disord. 1999:23:793-800.

22. Matsumoto T, Miyawaki C, Ue H, Yuasa T, Miyatsuji A, Moritani T. Effects of capsaicin-containing yellow curry sauce on sympathetic nervous system activity and diet-induced thermogenesis in lean and obese young women. J Nutr Sci Vitaminol (Tokyo). 2000:46:309-15.

23. Hamaoka T, McCully KK, Quaresima V, Yamamoto K, Chance B. Near-infrared spectroscopy/imaging for monitoring muscle oxygenation and oxidative metabolism in healthy and diseased humans. J Biomed Opt. 2007; 12:062105

24. Ekuni D, Takeuchi N, Furuta M, Tomofuji T, Morita M. Relationship between malocclusion and heart rate variability indices in young adults: a pilot study. Methods Inf Med. 2011:50:358-63.

25. Ohara K, Inoue Y, Sumi Y, Morikawa M, Matsuda S, Okamoto K, Tanaka H. Oxidative stress and heart rate variability in patients with vertigo. Acute Med Surg. 2015;2:163-8

26. Ahn JM. Heart Rate Variability (HRV) analysis using simultaneous handgrip electrocardiogram and fingertip photoplethysmogram. Adv Inf Sci Serv Sci. 2013:5:164-70

27. Sugawara N, Yasui-Furukori N, Sato Y, Saito M, Furukori H, Nakagami T, et al. Dietary patterns are associated with obesity in Japanese patients with schizophrenia. BMC Psychiatry. 2014;14:184.

28. Kanda K. Investigation of the freely available easy-to-use software 'EZR' for medical statistics. Bone Marrow Transplant. 2013;48:452-8.

29. Stewart S, McIntyre K, Capewell S, McMurray JJ. Heart failure in a cold climate. Seasonal variation in heart failure-related morbidity and mortality. J Am Coll Cardiol. 2002:39:760-6.

30. Hopstock LA, Barnett AG, Bønaa KH, Mannsverk J, Njølstad I, Wilsgaard T. Seasonal variation in cardiovascular disease risk factors in a subarctic population: the Tromsø Study 1979-2008. J Epidemiol Community Health. 2013;67:113-8.

31. Woodhouse PR, Khaw KT, Plummer M. Seasonal variation of blood pressure and its relationship to ambient temperature in an elderly population. Jypertens. 1993;11:1267-74.

32. Alpérovitch $A$, Lacombe JM, Hanon $O$, Dartigues JF, Ritchie $K$, Ducimetière $P$ et al. Relationship between blood pressure and outdoor temperature in a large sample of elderly individuals: the Three-City study. Arch Intern Med. 2009:169:75-80.

33. PModesti PA. Season, temperature and blood pressure: a complex interaction. Eur J Intern Med. 2013;24:604-7.

34. Seravalle G, Mancia G, Grassi G. Role of the sympathetic nervous system in hypertension and hypertension-related cardiovascular disease. High Blood Press Cardiovasc Prev. 2014;21:89-105.

35. Seravalle G, Grassi G. Sympathetic nervous system, hypertension, obesity and metabolic syndrome. High Blood Press Cardiovasc Prev. 2016:23:175-9.

36. Radke KJ, Izzo JL Jr. Seasonal variation in haemodynamics and blood pressure-regulating hormones. J Hum Hypertens. 2010;24:410-6.

37. Kristal-Boneh E, Froom P, Harari G, Malik M, Ribak J. Summer-winter differences in $24 \mathrm{~h}$ variability of heart rate. J Cardiovasc Risk. 2000;7:141-6.

38. Bahler L, Molenaars RJ, Verberne HJ, Holleman F. Role of the autonomic nervous system in activation of human brown adipose tissue: a review of the literature. Diabetes Metab. 2015;41:437-45.

39. Parysow O, Mollerach AM, Jager V, Racioppi S, San Roman J, Gerbaudo VH Low-dose oral propranolol could reduce brown adipose tissue F-18 FDG uptake in patients undergoing PET scans. Clin Nucl Med. 2007;32:351-7. 
40. Okuyama C, Sakane N, Yoshida T, Shima K, Kurosawa H, Kumamoto K, et al. (123)|- or (125)|-metaiodobenzylguanidine visualization of brown adipose tissue. J Nucl Med. 2002;43:1234-40.

41. Ulaner GA, Samstein R, Cahlon O, Weber WA, Rimner A. Unilateral suppression of brown fat on FDG PET/CT in Horner syndrome. Clin Nucl Med. 2016:41:797-8.

42. Wang Q, Zhang M, Ning G, Gu W, Su T, Xu M, et al. Brown adipose tissue in humans is activated by elevated plasma catecholamines levels and is inversely related to central obesity. PLoS One. 2011;6:e21006.

43. Rao RR, Long JZ, White JP, Svensson KJ, Lou J, Lokurkar I, et al. Meteorin-like is a hormone that regulates immune-adipose interactions to increase beige fat thermogenesis. Cell. 2014;157:1279-91.

44. Singhal V, Maffazioli GD, Ackerman KE, Lee H, Elia EF, Woolley R, et al. Effect of chronic athletic activity on brown fat in young women. PLoS One. 2016:11:e0156353.

45. Lynes MD, Leiria LO, Lundh M, Bartelt A, Shamsi F, Huang TL, et al. The cold-induced lipokine 12,13-diHOME promotes fatty acid transport into brown adipose tissue. Nat Med. 2017;23:631-7.

46. Hermann JM, Rosenbauer J, Dost A, Steigleder-Schweiger C, Kiess W, Schöfl C, et al. Seasonal variation in blood pressure in 162,135 patients with type 1 or type 2 diabetes mellitus. J Clin Hypertens (Greenwich). 2016;18:270-8.

47. Yoneshiro T, Aita S, Matsushita M, Kayahara T, Kameya T, Kawai Y, et al. Recruited brown adipose tissue as an antiobesity agent in humans. J Clin Invest. 2013;123:3404-8.

\section{Submit your next manuscript to BioMed Central} and we will help you at every step:

- We accept pre-submission inquiries

- Our selector tool helps you to find the most relevant journal

- We provide round the clock customer support

- Convenient online submission

- Thorough peer review

- Inclusion in PubMed and all major indexing services

- Maximum visibility for your research

Submit your manuscript at www.biomedcentral.com/submit
C Biomed Central 